\title{
¿Qué Tiene que Ver el Sexo con Eso? Los Desafíos para Incorporar la Sexualidad en la Planificación Familiar
}

Kirsten Moore

Population Council

Judith F. Helzner

Follow this and additional works at: https://knowledgecommons.popcouncil.org/departments_sbsr-pgy How does access to this work benefit you? Let us know!

\section{Recommended Citation}

Moore, Kirsten and Judith F. Helzner. 1996. "¿Qué Tiene que Ver el Sexo con Eso? Los Desafíos para Incorporar la Sexualidad en la Planificación Familiar." New York: Population Council and International Planned Parenthood Federation/Western Hemisphere Region. 


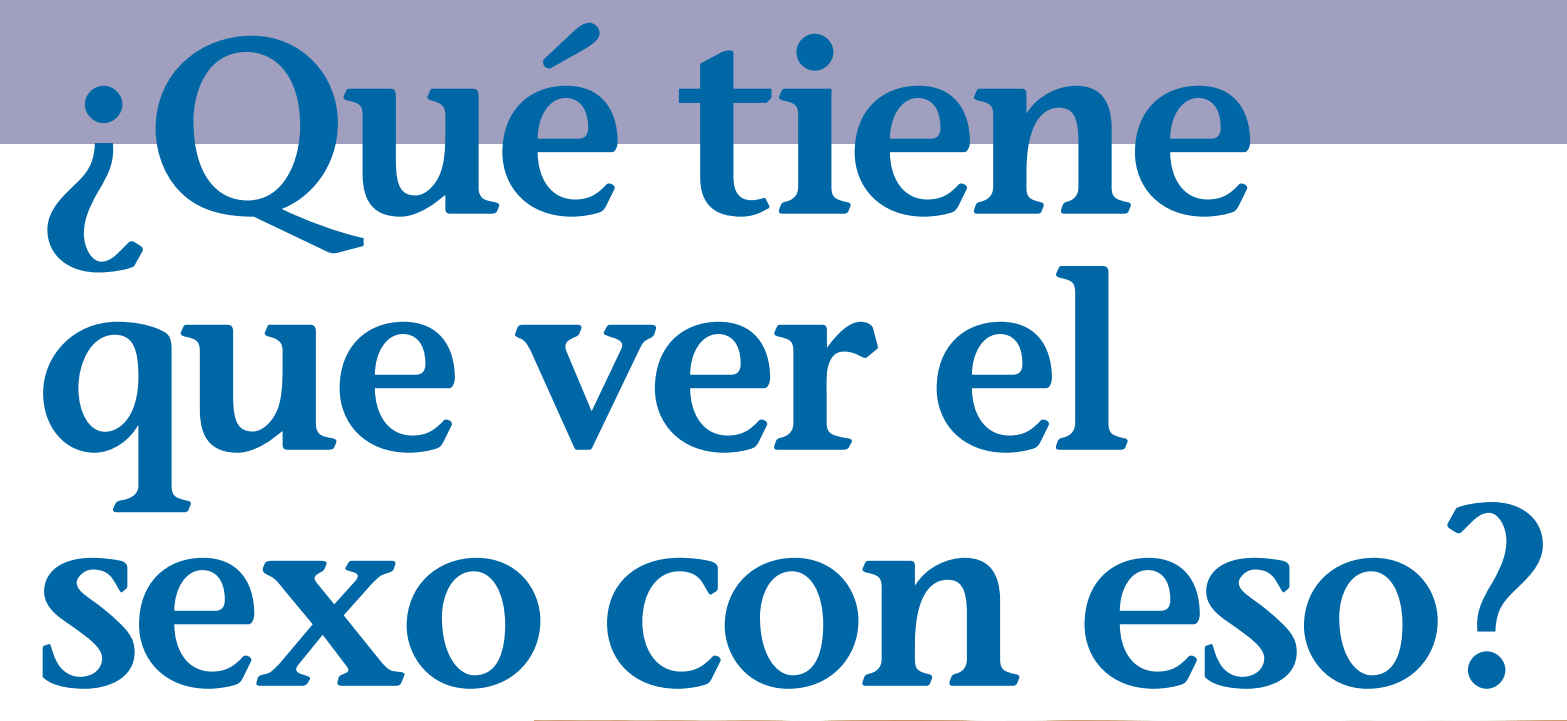

Los desafíos

para incorporar

la sexualidad en

la planificación

familiar 


\section{¿Qué tiene que ver el \\ sexo con eso?}

Los desafíos para incorporar la sexualidad en la planificación familiar

Kirsten Moore y Judith F. Helzner 


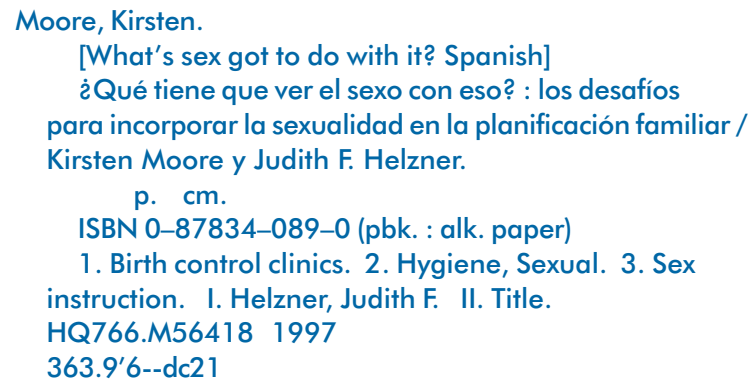

The Population Council busca mejorar el bienestar y la salud reproductiva de las generaciones actuales y futuras alrededor del mundo y ayudar a que se logre un equilibrio humanitario, equitativo y sustentable entre los seres humanos y los recursos. The Council, organización no gubernamental sin fines de lucro dedicada a la investigación, fue establecida en 1952, tiene una junta de directores multinacional; su oficina central en Nueva York apoya a una red global de oficinas regionales y nacionales.

Population Council

One Dag Hammarskjold Plaza

New York, NY 10017 USA

tel: (212) 339-0500

fax: (212) 755-6052

email: pubinfo@popcouncil.org

http://www.popcouncil.org

La Federación Internacional de Planificación de la Familia/Región del Hemisferio Occidental Inc. (IPPF/RHO) y sus 46 asociaciones de planificación familiar afiliadas, promueven que se reconozca y se ejerza la planificación familiar como derecho humano básico, dentro del contexto del plan estratégico mundial de la IPPF "Visión 2000." Este Plan dirije a las organizaciones de planificación familiar alrededor del mundo, para que trabajen en respuesta a seis desafíos: Responder a necesidades no satisfechas, mejorar la salud sexual y reproductiva, eliminar el aborto inseguro, trabajar en pro del empoderamiento de la mujer, encarar las necesidades de la juventud y promover la calidad de atención.

IPPF/WHR, Inc. 120 Wall Street New York, NY 10005-3902 USA tel: (212) 248-6400 fax: (212) 248-4221 email: info@ippfwhr.org http://www.ippfwhr.org 


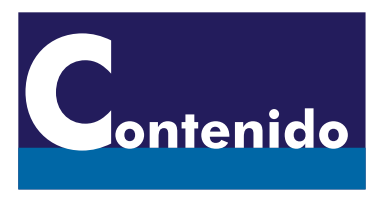

Prefacio

Mito No. 1: La sexualidad es un asunto personal que la gente no está dispuesta a discutir.

Mito No. 2: El sexo es una actividad voluntaria entre individuos de igual condición.

Mito No. 3: Las/los clientes prefieren los métodos de planificación familiar que no interfieren con el coito.

Mito No. 4: Las/los prestadoras/es de servicios están preparadas/os para responder a las preguntas y necesidades de las/los clientes referentes a la sexualidad.

Mito No. 5: Referirse a la sexualidad resultará una carga adicional para los programas de planificación familiar.

Poemas de los Talleres Comunitarios de la Belize Family Life Association 


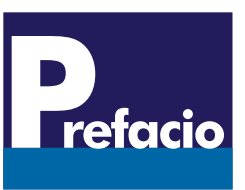

¿Q

ué tiene que ver el sexo con eso? Para las personas que trabajan en el diseño de programas de planificación familiar o realizan investigaciones respecto a dichos programas, la respuesta puede parecer obvia. Pero en la práctica, rara vez se reconoce tal conexión. Durante décadas, los programas de planificación familiar han sido diseñados bajo el supuesto de que el hecho de proporcionar información y tecnologías a los clientes, los cuales son definidos casi exclusivamente como mujeres, será suficiente para reducir el número de embarazos no deseados y no planeados. En años recientes, las/los tomadoras/es de decisiones, las directoras/es de programas y las investigadoras/es han comenzado a ponerse de acuerdo respecto a la importancia de mejorar la calidad de los servicios de planificación familiar. Hoy en día, sin embargo, se reconoce cada vez más que aún no es suficiente con prestar más atención a las necesidades de las/de los clientes. Mientras los programas de planificación familiar ignoren el contexto dentro del cual individuos y parejas toman sus decisiones acerca de la fertilidad y la contracepción, su impacto y su efectividad seguirán siendo limitados. Además, la continua propagación de la pandemia del VIH y la creciente visibilidad de asuntos tales como los derechos de las mujeres y la coerción sexual están obligando a que mucha gente se replantee la necesidad de enfocarse en la reducción de los nacimientos no deseados.

Aquellas/os que trabajan en el campo de la investigación y de las innovaciones en la prestación de servicios en todo el mundo exploran cada vez más la complicada y dinámica conexión que existe entre sexualidad y planificación familiar. Por ejemplo, The Population Council y la International Women's Health Coalition han recopilado experiencias en cuanto a investigación y programas que permiten vislumbrar las percepciones y experiencias que tienen los hombres y las mujeres sobre su sexualidad y sus relaciones íntimas. Juntos publicaron un libro, Learning About Sexuality: A Practical Beginning (Aprendiendo sobre sexualidad: un comienzo práctico), que trata sobre cómo la sexualidad y las diferencias de poder entre hombres y mujeres moldean la práctica anticonceptiva y la salud reproductiva. También documenta cómo las/los activistas de base y las/los consejeras/os en el área de la planificación familiar y la salud reproductiva pueden ayudar a que los individuos lleguen a tener una vida sexual satisfactoria y un mayor bienestar. Por otra parte, en 1992, la Federación Internacional de Planificación de la Familia (IPPF) retó a las agencias de planificación familiar afiliadas alrededor del mundo para que experimentaran a través de los servicios a fin de mejorar la salud sexual y reproductiva. Desde entonces, la Región del Hemisferio Occidental de la IPPF (IPPF/RHO) ha logrado aprender más acerca de cómo la actitud de las/los prestadores respecto a la sexualidad y los roles de los géneros afectan los servicios que las/los clientes reciben. En 
consecuencia, la IPPF/RHO ha desarrollado innovadores enfoques para cambiar de esas actitudes a otras que puedan atender mejor las necesidades de sus clientes en cuanto a salud sexual.

Pensamos que sería valioso tanto para las/los investigadores como para las/los profesionales de la medicina unir estas dos perspectivas. En febrero de 1996, la IPPF/RHO y el Programa Ebert sobre Cuestiones Críticas en Salud Reproductiva del Population Council organizaron de manera conjunta una reunión para discutir el desafío que constituye incorporar la sexualidad en la planificación familiar. Nosotras elaboramos este informe después de concluir que las ideas y estrategias presentadas durante la reunión merecían un amplio reconocimiento y debate dentro del campo de la planificación familiar. Esperamos que esto sea un aliciente para que otras y otros que trabajan en este terreno reflexionen sobre cómo ofrecer servicios de planificación familiar y salud reproductiva de maneras que promuevan la capacidad del individuo para identificar y hacer frente a sus necesidades de salud sexual, y de maneras que enaltezcan la igualdad en la pareja. Este informe se basa principalmente en las discusiones de ese día, así como en nuestras perspectivas como organizadoras.

Muchas gracias a las presentadoras-Julie Becker, Ann Blanc, Debra Boyer, Margarita Diaz, Hilary Hughes, Robert Miller, Elaine Murphy, Jewel Quallo-Rosberg, Debbie Rogow, and Lindsay Stewart-cuyas experiencias y reflexiones constituyeron los cimientos de este informe. La ayuda de Judith Bruce y Elizabeth McGrory para aclarar nuestros objetivos y mensajes tanto en la reunión como en la elaboración de este informe resultó instrumental, mientras que Elizabeth Coleman, Victoria Jennings y Geeta Rao Gupta nos proporcionaron retroalimentación que fue de gran ayuda para que este informe llegara a un público más amplio. Diane Rubino se ocupó de manera intachable de las muchas facetas administrativas de este proyecto. Finalmente, queremos agradecer a nuestros respectivos donantes. Dentro de la IPPF/RHO, los fondos para la reunión y el informe fueron suministrados por la Fundación Ford. El Programa Ebert sobre Cuestiones Críticas en Salud Reproductiva del Population Council copatrocinó esta reunión con fondos de la Fundación John D. y Catherine T. MacArthur. La Fundación Ford, a través del Programa de Género, Familia y Desarrollo del Council, dio fondos adicionales para este informe.

Kirsten Moore, Population Council Judith F. Helzner, IPPF/RHO 


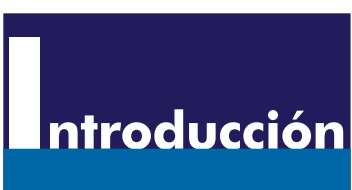

\section{$\mathrm{E}$} $\mathrm{n}$ años recientes, muchas directoras/es de programas de planificación familiar han comenzado a considerar la posibilidad de ofrecer, y cómo hacerlo, una gama más amplia de servicios de salud reproductiva, sobre todo en lo que se refiere a la prevención y el tratamiento de las enfermedades de transmisión sexual (ETS). Este interés, que en muchos países empezó como resultado de los intentos para hacer frente a la pandemia del SIDA, creció a raíz de la Conferencia Internacional sobre Desarrollo y Población en 1994. El Programa de Acción de dicha conferencia hace un llamado para que los servicios de planificación familiar sean colocados dentro de un marco de salud reproductiva que enfatice la salud y el bienestar del individuo, el empoderamiento de las mujeres y la equidad de género. Si los programas de planificación familiar quieren alcanzar estas metas, necesitan prestar mayor atención a cuestiones como la sexualidad y la distribución de poder en las relaciones familiares e íntimas.

El estrecho alcance de los programas de planificación familiar rara vez se refiere a las normas tan diferentes en cuanto al comportamiento sexual y reproductivo de hombres y mujeres. Además, gran parte del personal de estos programas piensa que la conducta sexual y reproductiva es un reflejo de la cultura y que los servicios de planificación familiar no pueden o no deben interferir en esta área. En tanto otros creen que las dinámicas de poder y género son esenciales para lograr el uso seguro y efectivo de la anticoncepción, luchan por incluir estas cuestiones dentro de sistemas diseñados, financiados y evaluados de acuerdo a indicadores tan limitados como "aceptantes" de anticonceptivos y nacimientos evitados. Aprender más acerca de las dinámicas de poder dentro de las relaciones íntimas, y tratar de alterarlas, presenta retos fundamentales para la investigación y los programas de planificación familiar.

A fin de involucrar a las/los directores de programas internacionales y a las/los investigadores en este proceso de aprendizaje, la International Planned Parenthood Federation/Región del Hemisferio Occidental (IPPF/RHO) y el Programa Robert H. Ebert sobre Cuestiones Críticas en la Salud Reproductiva del Population Council realizaron el 6 de febrero de 1996 un taller llamado: “Qué tiene que ver el sexo con eso? Los desafíos para incorporar la sexualidad en la planificación familiar.” (La lista completa de participantes aparece en las páginas 29-31.) Durante la discusión del día sobresalió la necesidad de que los programas de planificación familiar presten mayor atención a las implicaciones que tiene el contexto social de la/del cliente, particularmente en lo que se refiere a las relaciones de pareja y la conducta sexual, con el fin de asegurar la elección del método adecuado y el uso de éste. Además, las iniciativas tan innovadoras que ahí se discutieron indican que los programas de planificación familiar pueden tener y tienen un papel que jugar para ayudar a los 
individuos y a las parejas a que desarrollen mayores capacidades de autoconciencia, comunicación y toma de decisiones respecto de su propia conducta sexual y reproductiva. En la reunión se examinaron cinco mitos que han impedido que los servicios de salud reproductiva y planificación familiar se ocupen de manera directa de cuestiones relacionadas con la sexualidad y el género. Estos mitos son:

1. La sexualidad es un asunto personal que la gente no está dispuesta a discutir.

2. El sexo es una actividad voluntaria entre individuos de igual condición.

3. Las/los clientes prefieren los métodos de planificación familiar que no interfieren con el coito.

4. Las/los prestadoras/es de servicios están preparadas/os para responder a las preguntas y necesidades de las/los clientes referentes a la sexualidad.

5. Referirse a la sexualidad resultará una carga adicional para los programas de planificación familiar.

Además de explorar las raíces de estos mitos, las/los investigadores y personal de programas de planificación familiar compartieron estrategias que les han funcionado para superar los desafíos prácticos que han enfrentado al intentar que se dé un mayor reconocimiento a la sexualidad y al género en su trabajo

Entre las/los participantes estuvieron representantes de organizaciones con base en los Estados Unidos dedicadas ya sea a proporcionar información y servicios de planificación familiar a nivel internacional, realizar trabajos de investigación y entrenamiento dentro de tales programas, o a financiar trabajos en esta área. Además, había varias/os participantes de programas de planificación familiar con base en América Latina. (Hubo traducción simultánea para las oradoras/es tanto en español como en inglés.) Las presentaciones fueron hechas por profesionales que han trabajado en países en vías de desarrollo y en Estados Unidos.

Cabe señalar que cuando nos referimos en este informe a "servicios de salud reproductiva y planificación familiar," estamos hablando de una gama de temasincluyendo sexualidad, roles de género y toma de decisiones sexuales-que son cruciales para proporcionar información y asesoría sobre la prevención de ETS y VIH, así como sobre el cuidado después del parto, aborto y post aborto.

Como Kirsten Moore del Population Council sugirió en su presentación inicial, "sexualidad" es un término complejo y a menudo confuso que puede ser utilizado para describir tanto la conducta individual como las normas culturales. En este informe, se refiere a una construcción social de un impulso biológico. Es dinámico y multidimensional. La gente deriva su identidad sexual de su pareja, actos y conductas, impulso fisiológico y los significados que ellos les dan a estas cosas. La experiencia adquirida a través de la investigación y los programas demuestra que las mujeres con frecuencia ejercen poco poder respecto a la elección de sus parejas sexuales, a su participación en actividades sexuales y a cómo protegerse de enfermedades y embarazos no deseados. En consecuencia, los programas de planificación familiar están experimentando con nuevas formas para “atraer a los hombres." La idea no es simplemente aumentar el número total de usuarios de anticonceptivos, señaló Moore. Las estrategias de los programas deben reconocer que los encuentros sexuales forzados y las desigualdades de poder entre la pareja conducen a embarazos no deseados, enfermedades y otros resultados no deseables. Ayudar a los individuos a desarrollar una mayor comprensión de su sexualidad y de las motivaciones de su comportamiento sexual es un paso necesario para que dichas/os clientes alcancen sus intenciones reproductivas. Además, puede llegar a ser una experiencia profundamente fortalecedora para el/la cliente o la pareja. 
Al hacer la conexión entre sexualidad y planificación familiar, Moore advirtió que es vital que las/los profesionales de la salud pública hablen en términos positivos. Muy a menudo, nuestros roles profesionales nos llevan a hablar solamente del "riesgo" de un embarazo no deseado, la "amenaza" de ser infectado con el virus que causa el SIDA, o el "peligro" del abuso y la coerción sexual. Sin embargo, de manera individual la mayoría de nosotras/os piensa de manera más positiva respecto a nuestra propia sexualidad. Nosotras/os consideramos las posibilidades del placer, de construir relaciones íntimas, de tener un hijo. Nuestra tarea como individuos y profesionales es ayudar a las/los clientes a encontrar un equilibrio entre placer y riesgo. Esto significa explorar de manera activa, con clientes o clientes en potencia, la disonancia entre las nociones culturales de lo que significa un comportamiento sexual adecuado para hombres y mujeres y la conducta real del individuo.

La experiencia muestra que es posible que los programas de planificación familiar se refieran de manera efectiva a cuestiones de sexualidad y relaciones, afirmó Judith Helzner de la IPPF/RHO al cierre de la reunión. Además, ofrecer estos servicios tiene el potencial de atraer clientes y de hacer que el personal se sienta más satisfecho con su trabajo. Helzner hizo notar que, en efecto, muchas de las presentaciones de ese día hicieron énfasis en que la sexualidad y el comportamiento sexual son integrales para el funcionamiento de los programas de planificación familiar, y no simplemente un añadido. Las/los directores de los programas deben considerar la comprensión de la/del cliente respecto de su sexualidad y el contexto en el que ocurren las relaciones sexuales de dicha/o cliente como puntos de arranque importantes cuando se elaboren las campañas de información, educación y comunicación, o bien cuando se desarrollen enfoques de consejería. Esta atención a la sexualidad requiere de una nueva apreciación del alcance que tienen las estrategias para regular la fecundidad, así como un nuevo lenguaje que facilite la comunicación con las/los clientes al hablar de cuestiones tan íntimas.

Al reflexionar sobre las experiencias de la IPPF, Helzner manifestó que los programas innovadores por lo general empiezan con una buena disposición para escuchar cuidadosamente las necesidades y experiencias de la gente, así como con una buena disposición para experimentar. Algunos programas son enfocados para ofrecer a la gente más información sobre su cuerpo o preguntarle si les gustaría incluir a su pareja en futuras sesiones de consejería. Otros son enfocados para ayudar a que las/los clientes desarrollen capacidades de comunicación y toma de decisiones, mismas que pueden servirles para negociar cambios en el comportamiento sexual y el uso de anticonceptivos con sus parejas. Analizar y cuantificar algunos de estos cambios será necesario para ayudar a justificar una mayor inversión en esta área y para mantener este ímpetu.

En casi cualquier situación, las políticas en torno a las cuestiones de sexualidad son por lo general bastante complicadas y a veces contradictorias, $\mathrm{y}$ requieren de una planificación cuidadosa por parte de aquellas/os que buscan llevar a cabo este trabajo. Este informe presenta algunas lecciones prácticas para las/los investigadores que estudian la sexualidad y para las/los directoras/es que desean incorporar la sexualidad en sus programas de planificación familiar. 

que la gente no está dispuesta a discutir.
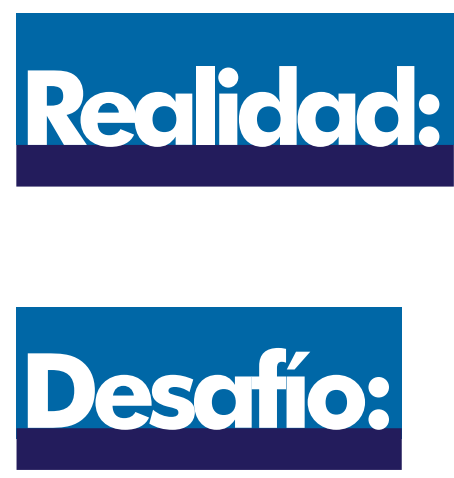

Precisamente porque la actividad sexual es tan privada es que la gente anhelan oportunidades constructivas en que puedan hablar de sus experiencias, preocupaciones ynecesidades sexuales.

\section{Encontrar forma de hacer que las personas se sientan más cómodas cuando hablan sobre su vida sexual con las/los trabajadoras/es e investigadoras/es en el área de la planificación familiar.}

E el mundo hay una escasez de buena información acerca del comportamiento sexual de los individuos. Muchos lo atribuyen al hecho de que investigar sobre este tema resulta difícil, si no imposible. En un principio, las/los demógrafas/os y las/los científicos sociales se mostraban escépticos en lo que se refiere a si era factible y apropiado preguntarle a las mujeres sobre el uso de anticonceptivos. Pero a medida que el campo de los estudios de población se desarrolló, las preguntas relacionadas a la salud, las intenciones reproductivas, el uso de anticonceptivos y las conductas sexuales fueron incorporadas de manera rutinaria en las Encuestas Mundiales de Fecundidad y las subsiguientes Encuestas de Demografía y Salud (EDS). Para finales de 1995, estas encuestas habían sido realizadas en 60 países, a menudo hasta dos y tres veces, informó Ann Blanc de EDS. Pocos mujeres y hombres se negaron a responder preguntas personales acerca de la frecuencia con que practican el coito, señaló Blanc. Algunas/os prestadores de servicios también cuestionaron a sus clientes respecto a sus conductas sexuales. De acuerdo con los estudios de observación para el Análisis Situaciónal, un 36 por ciento de prestadoras/es de servicios en Kenya le preguntaron a sus clientes acerca de la naturaleza de sus relaciones sexuales. En Zanzíbar, la cifra fue del 59 por ciento.

Contar con información precisa es algo crítico cuando se diseñan servicios que son sensibles a las necesidades de las mujeres. Blanc citó el ejemplo de las mujeres casadas que reportan una baja frecuencia coital porque sus maridos emigraron a un área urbana o bien a otro país en busca de trabajo. Estas mujeres desearían un método anticonceptivo que pudieran usar sólo cuando tienen sexo. Si muchas mujeres en una comunidad reportan preferencias anticonceptivas similares, las clínicas podrían reorientar sus servicios entrenando consejeras/os y prestadoras/es de servicios, y asegurando un abastecimiento estable de métodos de barrera.

Algunas preguntas que podrían contener valiosa información incluyen: ¿Quiénes son sus parejas? ¿Tiene sus parejas otras compañeras/os sexuales? ¿Con qué frecuencia tienen relaciones sexuales? ¿Qué clase de relaciones sexuales tienen? ¿Cuáles son sus percepciones del placer? ¿Cuáles son sus percepciones del riesgo? ¿Quién decide cuándo tener relaciones sexuales? Si la pareja no lo desea, ¿qué estrategias 
utilizan ella o él para negarse? ¿Influyen las nociones de paternidad y/o pareja en el comportamiento sexual? Las/los programadoras/es e investigadoras/es que buscan respuestas a estas preguntas todavía están aprendiendo cuáles son las formas más apropiadas y óptimas para generar información confiable. Geeta Rao Gupta hizo notar que las investigadoras que condujeron un estudio apoyado por el Programa de Investigación sobre la Mujer y el SIDA encontraron que las mujeres jóvenes en Tailandia se sentían más cómodas hablando cara a cara que contestando un cuestionario por escrito. Sugirió que esto podía deberse a que la acción de escribir sus respuestas hacía que su comportamiento pareciera más real de lo que ellas estaban preparadas para reconocer, inclusive ante sí mismas.

Hilary Hughes de IPPF habló sobre la necesidad de encontrar nuevas maneras para reunir información sensible. El Proyecto de Salud Sexual (PSS) de la IPPF, cuyos servicios se refieren tanto a la planificación familiar como a la prevención y cuidado de las ETS y el VIH, ha incursionado en Gambia, Ghana, Tanzania, Burkina Faso, India y la República Dominicana sobre cómo lograr que la gente hable de cuestiones que afectan su vida. El personal del proyecto empieza generando discusiones entre grupos de comunidades diferentes en torno a cuestiones concretas relacionadas con la salud sexual y reproductiva, incluyendo la calidad de las relaciones hombre/ mujer; la capacidad de disfrutar las relaciones sexuales sin temer un embarazo no deseado, una enfermedad o la violencia, y las preocupaciones respecto a la posibilidad de concebir. La comunidad prioriza entonces sus preocupaciones más importantes, sugiere indicadores para medir el cambio e identifica agentes y métodos para la recolección de información. En Tanzania, por ejemplo, la comunidad identificó tres preocupaciones clave: el alcoholismo, que puede llevar a la ruptura de las relaciones dentro de las familias que libran una lucha económica; la promiscuidad, que puede llevar a la discordia entre parejas y a la falta de confianza y respeto en las relaciones sexuales; y el embarazo entre adolescentes. Referente a la promiscuidad, los miembros de la comunidad recomendaron los siguientes indicadores: el número de divorcios o separaciones en un periodo de tiempo definido; el número de problemas en la relación que llevaron a buscar ayuda externa; y el número de maridos que golpean a sus esposas o se involucran en otras formas de violencia doméstica. Las fuentes sugeridas para la recolección de información incluyeron a agentes de distribución comunitaria, consejeras/os tradicionales, los mayores de la comunidad, y una muestra de la población adulta sexualmente activa identificada a través de un cuestionario comunitario.

Estas discusiones le brindaron al personal del PSS una oportunidad para contestar preguntas, corregir conceptos o información erróneos y explorar los mitos relacionados con la salud sexual y reproductiva. Con frecuencia, las mujeres y los hombres usan vulgarismos o eufemismos que pueden no ser detectados de inmediato por una investigadora/or o personal clínico. Al reconocer estos términos, el personal clínico y del PSS puede emplear un lenguaje apropiado en instrumentos de investigación y en la consejería individual.

El PSS encontró que aunque la sexualidad es un asunto personal, también es una cuestión comunitaria. Los problemas que las personas experimentaron no fueron simplemente resultado del comportamiento individual sino que estuvieron influenciados por las normas y condiciones de la propia comunidad, tales como roles de género, oportunidades económicas, o el poder de los mayores. El personal del PSS se ha encontrado con que las discusiones sobre la sexualidad y la interacción entre mujeres y hombres, tanto dentro de la comunidad como en la clínica, pueden ser un poderoso punto de arranque para el cambio social. Por ejemplo, las discusiones sobre la discordia marital en una aldea de Ghana produjeron una amplia gama de opiniones 
diferentes por parte de hombres y mujeres. Conforme las discusiones progresaron, las mujeres y los hombres comenzaron a apreciar las causas de raíz, a escucharse unos a los otros y eventualmente a crear soluciones.

Los grupos bien facilitados o las discusiones comunitarias sobre cuestiones sensibles no sólo proporcionan información valiosa sino que también constituyen un servicio para las/los clientes y clientes en potencia. El PSS ha encontrado que el grupo permite que la gente desarrolle una mejor comunicación con aquellos/as con quienes están en conflicto y conforme visiones alternativas para el futuro. Como se demuestra la siguiente sección, inclusive las víctimas de abuso o coerción informan que simplemente el preguntárseles acerca de su experiencia puede ser algo catártico y benéfico. 
Las dinámicas de poder dentro de una relación de pareja influencian tremendamente la actividad sexual; un número significativo de mujeres y niñas, y a veces niños, informan que son coercionados a tener relaciones sexuales.

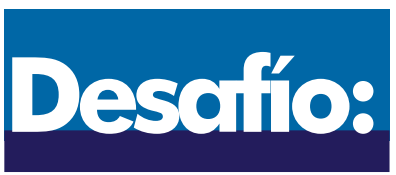

$E$ años recientes, los datos cuantitativos y cualitativos han desafiado el supuesto de que los clientes (generalmente mujeres) que solicitan servicios de planificación familiar están involucrados en relaciones sexuales monogámicas y de consenso. Estos datos revelan que una proporción importante de mujeres, niñas y a veces niños es forzada, obligada o engañada para tener sexo. Debra Boyer del Center for Health Training y Lindsay Stewart de IPPF/RHO presentaron datos sobre abuso recogidos en clínicas de planificación familiar en los Estados Unidos y América Latina. Revisaron lo que se conoce o lo que se considera como hipótesis en la literatura acerca de las conexiones que existen entre las experiencias de abuso y coerción y el uso de anticonceptivos; y presentaron algunos ejemplos de lo que las clínicas pueden hacer para responder mejor a las necesidades de sus clientes.

Boyer reportó hallazgos provenientes de un estudio realizado recientemente en catorce clínicas de planificación familiar en cinco estados de los Estados Unidos. Las/los investigadores les preguntaron a 2,226 mujeres sobre las experiencias de abuso físico, sexual y emocional que han padecido en su vida. Una tercera parte de las mujeres informó haber sufrido abuso sexual y una tercera parte reportó casos de violencia. Stewart presentó datos similares procedentes de otras partes del mundo. En cada caso, un sorprendente número de mujeres reportó una historia de abuso físico, sexual o emocional, a menudo ocurrida a temprana edad; una gran mayoría de estas mujeres conocía a sus abusadores.

Además, tanto Boyer como Stewart presentaron datos que indica una fuerte correlación entre el abuso sexual o coerción y el embarazo en adolescentes. Estudios efectuados tanto en países desarrollados como en vías de desarrollo revelan que las niñas y las mujeres que han sido abusadas sexualmente tienen un sentido de disociación, o una falta de conexión física con su cuerpo. También tienen una baja autoestima y con frecuencia sienten que no son amadas. Como resultado, a menudo son incapaces de fijar límites claros y adecuados, sobre todo en relación a sus propios cuerpos; es común que sean incapaces de decir “no." Esta información hace surgir dudas respecto a si puede decirse de manera precisa que las niñas que han sido abusadas sexualmente han "consentido" a tener actividad sexual. 
Boyer y una colega condujeron un estudio temprano en clínicas de planificación familiar en el estado de Washington. Sus hallazgos revelan que el abuso sexual está fuertemente relacionado a las siguientes situaciones: tener sexo a edad más temprana, un mayor número de parejas sexuales, mayor disparidad en cuanto a la edad con las parejas, uso más frecuente de alcohol y drogas (lo cual puede conducir a una conducta sexual de alto riesgo), y uso menos frecuente de anticonceptivos. También constituye el más importante factor de pronóstico en cuanto a embarazos repetidos. De hecho, diez años de investigación en esta área llevaron a Boyer a desarrollar la hipótesis de que el abuso sexual es quizás el principal indicador en lo que se refiere a los embarazos no deseados en adolescentes en los Estados Unidos. Este patrón puede no resultar cierto en países en vías de desarrollo, en donde es frecuente que las mujeres se casen a edades más tempranas. Sin embargo, el abuso físico, emocional y sexual encierra perturbadoras implicaciones que llevan a desarrollar futuros patrones de comportamiento sexual, así como nocivas consecuencias para la salud física y sicosocial.

En otro estudio las asociaciones afiliadas a la IPPF/RHO en Perú y Colombia reunieron información sobre experiencias de abuso sexual entre jóvenes que acudieron en busca de consejería médica y psicológica. Más de la mitad dijo que fueron abusadas/ os sexualmente en los 12 meses anteriores, o mostraron señales de abuso sexual reciente. Aunque la muestra fue selectiva, los hallazgos sugieren que el abuso sexual está estrechamente relacionado al sexo de alto riesgo y a los embarazos no deseados.

Debbie Rogow (consultora independiente) sugirió que, dada la historia del abuso, la categoría descriptiva de "activa sexualmente" puede resultar un nombre inapropiado. Muchas mujeres jóvenes que están teniendo sexo podrían ser descritas con mayor precisión como "aceptantes sexuales" y no como "activas sexualmente." Además, la palabra "activa" podría usarse mejor para describir a las jóvenes y las mujeres que deciden en beneficio propio-sea la decisión tener relaciones sexuales, o no tenerlas.

Margaret Hempel de la Fundación Ford señaló que muchas jóvenes carecen de lenguaje positivo con el cual describir su sexualidad, sus deseos y sus experiencias. Dijo que es crítico promover una identidad sexual saludable entre las jóvenes que les permita desarrollar límites apropiados, sentirse orgullosas de sus cuerpos y tomar decisiones que tengan que ver con su salud. Martha Brady del Population Council añadió que la participación en un amplio rango de actividades deportivas, desde el basketball hasta la danza, podría ayudar a las jóvenes a desarrollar una autoimagen más positiva y un sentido de control.

Aunque los muchachos y los hombres también experimentan el abuso sexual, y a veces las perpetradoras de abuso, coerción sexual y violencia son mujeres, el número de hombres abusadores es abrumadoramente mayor que el de mujeres. Las explicaciones en este sentido todavía están surgiendo y son impugnadas. Sin embargo, existe la creencia ampliamente esparcida de que las definiciones culturales de masculinidad y feminidad tienen implicaciones dañinas para mujeres y hombres. De hecho, estas nociones de masculinidad y feminidad deben cambiar si se desea que las niñas y las mujeres desarrollen un mayor sentido de protagonista. Los programas de educación acerca de la prevención del embarazo y las enfermedades pueden ayudar a que los hombres y los muchachos desarrollen un sentido más saludable de hombría y hablen acerca de lo que se necesita para llegar a ser un buen amante, compañero o padre. Los hombres y los muchachos pueden apreciar la oportunidad de aprender más acerca de la fisiología reproductora y la salud de las mujeres a las que aman. Y podrían llegar a apoyar las elecciones reproductivas de las mujeres y a volverse parejas responsables. 
El recoger datos sobre abuso sexual presenta un número de desafíos, incluyendo algunas preocupaciones éticas importantes. Por ejemplo, Boyer declaró que ella piensa que no es apropiado preguntarle a las/los clientes acerca de abusos pasados o actuales utilizando cuestionarios anónimos. En vez de esto, el personal de la clínica debería establecer una relación con sus clientes y referirlas a servicios médicos o de consejería externos, o bien a servicios legales cuando éstos sean requeridos.

Las/los investigadoras/es casi invariablemente reportan que las mujeres que han sido abusadas agradecen el que se les pregunte acerca de sus experiencias. Para muchas, es la primera oportunidad de confiar en alguien, de hacer preguntas o de enfrentarse a sus sentimientos. A pesar de cierta renuencia inicial, el personal de varias clínicas habló posteriormente de la satisfacción que experimentan después de haber logrado un intercambio más abierto con sus clientes. El personal de INPPARES en Perú también informa que ha logrado una mejor comunicación con sus clientes y sus colegas como resultado de un trato más abierto y explícito de la cuestión del abuso sexual. Esta experiencia ha llevado a que personal de Perú y Colombia, por ejemplo, desarrollen nuevos programas educativos encaminados a prevenir el abuso sexual, así como nuevos servicios para ayudar a las víctimas de abuso.

Al diseñar y suministrar servicios, es crucial no asumir que las/los clientes participan en relaciones sexuales consensuales. Aunque el tema de la coerción y el abuso sexual resulte tan problemático, tanto las/los clientes como las/los prestadoras/es de servicios se benefician de las oportunidades para mujeres y hombres, y niñas y niños, de revelar y discutir sus experiencias. Pero las relaciones abusivas no son lo único que las/los profesionales en el campo de la planificación familiar deben esperar. En muchos casos, las limitadas opciones sexuales y reproductivas surgen de normas sociales respecto a las relaciones de género entre mujeres y hombres. 


\section{Mito No.3:}

Las/los clientes prefieren los métodos de planificación familiar que no interfieren con el coito.

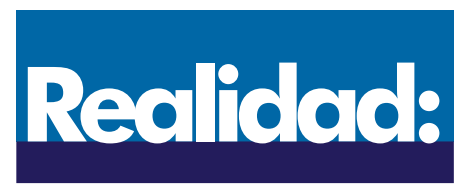

La tendencia de las usuarias de escoger métodos no asociados al coito está típicamente más influenciada por factores tales como prejuicios de las/los prestadores y las preocupaciones de sus parejas masculinas más que consideración a sus propias necesidades yopciones.

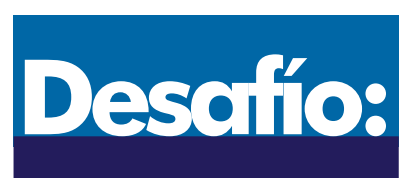

Ayudar a las/los clientes a tomar decisiones informadas acerca del método que resulte mejor para su relación y sus necesidades.

_os atributos positivos y negativos que las/los prestadoras/es generalmente asignan a los distintos métodos anticonceptivos, observó Debbie Rogow, "descansan en un cuerpo de literatura casi mítica: historias que han llegado a estar tan profundamente arraigadas que las bases sobre las cuales fueron construidas ya ni siquiera se cuestionan." Rogow, consultora independiente, y Margarita Diaz, enfermera profesional de la Universidad de Campinas en Brasil, efectuaron una revisión de las actitudes de las/los prestadoras/es de servicios respecto a los métodos de barrera y los métodos para los hombres. Su análisis mostró cómo el origen de las “desventajas” de dichos métodos proviene de las preocupaciones masculinas respecto al coito.

Díaz citó algunas de las nociones más comunes que las/los prestadores de servicios mantienen en relación a los métodos de barrera para las mujeres, inclusive el diafragma, el tapón cervical y el condón femenino: las mujeres no pueden aprender a usar estos métodos de manera apropiada; su efectividad es muy baja; a las mujeres no les gusta manipular sus genitales; los maridos no aceptarán o apoyarán el uso de estos métodos; y estos métodos reducen el placer sexual del hombre. Con frecuencia, estos prejuicios son comunicados ya sea a propósito o de manera inconsciente a las/los clientes durante las sesiones de consejería. Eventualmente, el hecho de que los índices de aceptación de métodos que no interfieren con el coito son más altos, es utilizado para respaldar la conclusión de que las/los clientes prefieren métodos que no sean de barrera. Este argumento no sólo resulta circular, observó Díaz, sino que a menudo no logra reflejar los intereses de las/los clientes. Antes de diseñar un curso sobre sexualidad para mujeres clientes de planificación familiar, ella y sus colegas realizaron entrevistas en una muestra al azar de 462 mujeres que asistían a sus clínicas y usaban métodos anticonceptivos diversos. Como se ilustra en el Cuadro 1, las mujeres no sintieron que su vida sexual empeorara como resultado de usar métodos de barrera. De hecho, más mujeres informaron una reducción en la satisfacción sexual al usar métodos hormonales.

En términos de métodos masculinos, observó Rogow, investigadoras/es y personal clínico se han negado repetidamente a investigar la interfase entre la comodidad sexual y la anticoncepción. Aunque se han gastado millones de dólares para estudiar los obstáculos que existen respecto al uso del condón, todavía tiene que elaborarse un cuestionario que les pregunte a los hombres si su temor a perder una erección al 


\section{Cuadro 1}

\section{Cambios en la vida sexual de acuerdo al método anticonceptivo utilizado}

\begin{tabular}{lllll} 
Método & Mejoró & Empeoró & Sin cambio & No información \\
\hline $\begin{array}{l}\text { Anticonceptivo oral } \\
(\mathrm{n}=71)\end{array}$ & $29.6 \%$ & $14.1 \%$ & $49.3 \%$ & $7.0 \%$ \\
$\begin{array}{l}\text { Inyectables } \\
(\mathrm{n}=134)\end{array}$ & 20.9 & 11.9 & 61.2 & 6.0 \\
$\begin{array}{l}\mathrm{DIU} \\
(\mathrm{n}=92)\end{array}$ & 30.4 & 13.0 & 53.3 & 3.3 \\
$\begin{array}{l}\text { Métodos de } \\
\text { barrera (n=25) }\end{array}$ & 24.0 & 4.0 & 68.0 & 4.0
\end{tabular}

Fuente: Diaz, M. 1995. En Learning About Sexuality, Sondra Zeidenstein y Kirsten Moore, eds. Nueva York: Population Council y International Women's Health Coalition.

ponerse un condón es un factor central en su renuencia a utilizar este método. Esto es a pesar de la evidencia anecdótica que indica que algunos hombres, especialmente los más jóvenes, prefieren usar condones porque les ayuda a mantener una erección durante más tiempo. Mientras tanto, la noción de que el condón disminuye la sensibilidad y el placer sexual del hombre durante la relación sexual ha sido concretamente conceptualizada en miles de folletos informativos acerca de los condones. En contraste, pocos folletos mencionan que el condón puede resultar incómodo para una mujer si no está excitada o tiene sequedad vaginal.

Al revisar la literatura respecto al método de retiro, Rogow concluyó que los mitos sobre su efectividad y efectos en cuanto a la satisfacción sexual han relegado el método de retiro más allá de la categoría de los métodos secundarios, a la categoría invisible pero muy popular de los que ni siguiera son considerados métodos. Tales creencias persisten pese al hecho de que el amplio uso del retiro es citado como uno de los principales catalizadores detrás de la transición de la fertilidad en Europa. Libros de texto médicos atribuyen una variedad de enfermedades psiquiátricas y urológicas al retiro, a pesar de que no existen investigaciones que documenten que este método tiene un efecto perjudicial grave sobre la satisfacción sexual masculina. De hecho, la poca investigación que hay indica que aquellos que usan el retiro, con frecuencia experimentan sentimientos positivos sobre cómo este método afecta su vida sexual.

Un énfasis sobre el placer sexual masculino y un enfoque sobre el modelo de conducta sexual de la relación pene-vagina domina el pensamiento y la práctica dentro del terreno de la planificación familiar. Esta práctica no sólo subordina la sexualidad femenina y las relaciones sexuales a la reproducción, sino que también eleva el placer sexual masculino más allá de la responsabilidad reproductiva. Esto afecta de manera grave el objetivo de ayudar a las/los clientes a usar de forma segura y efectiva los métodos anticonceptivos a fin de que logren sus intenciones reproductivas. Primero, socava la comunicación y la toma de decisiones conjunta respecto a las responsabilidades reproductivas y la conducta sexual. Segundo, limita la capacidad de la mujer para utilizar una amplia variedad de métodos $y$, tal vez, de ejercer algún control sobre su vida sexual. Finalmente, deja a las/los profesionales de la salud con opciones limitadas para ayudar a reducir la propagación de las ETS, el VIH y otras formas de morbilidad reproductiva.

Muchas/os en el campo de la planificación familiar están empezando a reconocer que el énfasis puesto en métodos (usualmente femeninos) modernos y en 
la exclusión de los métodos tradicionales ha socavado gravemente la participación del hombre en las decisiones relacionadas a la responsabilidad sexual y reproductiva. Uno de los resultados del énfasis puesto en las mujeres como clientes es que hay pocas fuentes de información y servicios que se ofrezcan directamente a los hombres. Igualmente significativo es el hecho de que también hay pocas oportunidades para que una mujer involucre a su compañero si así lo decide. Muchos hombres han internalizado el mensaje de que debido a que la mayoría de los métodos modernos son usados por mujeres, ellos no tienen que interrumpir o disminuir su propio placer sexual. Otros hombres, inclusive aquellos que han decidido reducir o espaciar los nacimientos, creen que evitar el embarazo es responsabilidad de la mujer.

El énfasis de las/los prestadoras/es de servicios en los métodos hormonales o los dispositivos intra-uterinos (DIU) y la exclusión de otros métodos puede limitar todavía más la capacidad de una mujer para decidir cuándo tener sexo, con quién y bajo qué condiciones, afirmó Erin McNeill de USAID. En muchos casos, se espera que una esposa esté, por definición, siempre disponible sexualmente para su marido. En estos ejemplos, los métodos como el diafragma, los condones y la abstinencia periódica pueden proporcionar a la mujer algún tipo de poder de negociación respecto al tiempo y a la frecuencia del sexo. En otras palabras, una mujer podría utilizar métodos de barrera $\mathrm{u}$ otro método dependiente del coito para lograr un respiro, impuesto externamente, en cuanto al sexo no deseado. Así, observó Rogow, la literatura y la consejería sobre planificación familiar puede no estar ayudando a las mujeres al quedar como un hecho implícito el mensaje de que no estar disponible sexualmente es una "desventaja" de un método.

Finalmente, el prejuicio profesional que considera los condones como un método menos efectivo y menos deseable para evitar el embarazo es un obstáculo para las/los médicos que están tratando de prevenir la transmisión del VIH/SIDA. Datos del Análisis Situacional en Senegal revela que en tanto las clínicas están bien surtidas de condones, éstos son mencionados a sólo una cuarta parte de las/los clientes nuevos; sólo el 2 por ciento de las/los clientes nuevos oyen hablar de los condones dentro del contexto de las enfermedades de transmisión sexual; y menos del 1 por ciento los recibe. Algo que también resulta problemático es el hecho de que hay clínicas y programas de planificación familiar en las cuales los condones son mencionados solamente en el contexto de la prevención de enfermedades. Potencialmente, esto podría enviar mensajes conflictivos a las/los clientes acerca de la efectividad de este método para también evitar los embarazos.

Se requieren nuevas investigaciones y enfoques que apoyen la capacidad de las/los clientes para tomar decisiones informadas y ponerlas en práctica respecto a cuáles son los métodos anticonceptivos más apropiados en sus respectivos casos. Las campañas de información, sugirió Rogow, podrían dirigirse directamente a las preocupaciones de los hombres sobre el uso del condón. Los distribuidores de condones podrían utilizar modelos de penes para mostrarle a los hombres cómo ponerse el condón correctamente y mostrarle a las mujeres cómo ponerles el condón a sus compañeros. Las clínicas podrían ofrecer clases de concientización sobre fertilidad para las mujeres que carecen de información sobre su cuerpo y su fisiología reproductiva, a fin de enriquecer su capacidad para tomar decisiones respecto al sexo y a la anticoncepción. Las/los prestadoras/es de servicios de planificación familiar deben educar a las/los clientes respecto a todos los métodos anticonceptivos, la planificación familiar natural y la abstinencia periódica para que ellas/ellos puedan comprender plenamente cómo los distintos métodos afectan el cuerpo y cómo es que provocan los efectos laterales que pueden haber experimentado. Este proceso ayudaría a aclarar la malinformación que con frecuencia se pasa por alto en una sesión de consejería. 
Si la meta de los servicios es ayudar a las/los clientes a lograr sus intenciones reproductivas, es un error que las/los prestadoras/es le asignen atributos absolutamente positivos y negativos a métodos específicos. Lo que es considerado como un beneficio o una desventaja de cada método puede ser diferente para cada cliente, dependiendo de sus propias necesidades y de la relación con su pareja. Ayudar a las/los prestadoras/es a superar algunos de sus prejuicios y establecer una mejor comunicación con sus clientes respecto a sus historias, relaciones, necesidades y objetivos es el tema de la siguiente sección. 


\section{Mito No.4:}

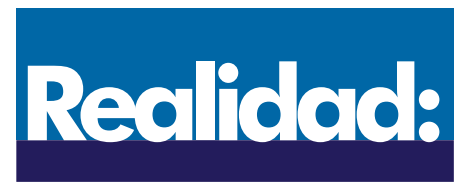

Las/los prestadoras/es de planificación familiar puede que sepan cómo explicar el uso apropriado de un método de planificación, pero muy pocas/os tienen el entrenamiento en cómo facilitar la comunicación con las usarias_particularmente sobre temas complejos e íntimos.

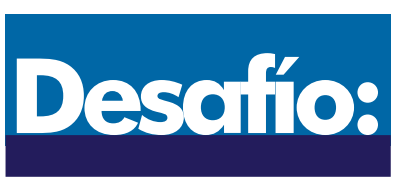

Las/los prestadoras/es de servicios las preguntas y necesidades de las/los clientes referentes a la sexualidad. están preparadas/os para responder a 
las habilidades, los valores y las actitudes del personal en relación al VIH. Los hallazgos revelaron un proceso un tanto didáctico de consejería en el cual la información sobre métodos era transmitida solamente del prestador al cliente. El personal consideraba a los condones como un método anticonceptivo secundario, con muy poca discusión de las ETS y prácticamente ninguna instrucción sobre cómo usarlos de manera adecuada. Generalmente les era más fácil tocar el tema de la sexualidad con las/los clientes más jóvenes que con las/los más viejas/os. Además, tendían a juzgar el comportamiento sexual de las/los clientes en base a sus propios valores y prejuicios. Algo positivo es que el personal tenía una percepción muy precisa del riesgo que corrían sus clientes de ser infectados con el VIH u otra ETS. Sin embargo, rara vez consideraron el contexto más amplio que influye en las opciones, decisiones y prácticas de sexo seguro de sus clientes. La mayoría de las/los prestadoras/es también carecía de la capacidad de ayudar a las/los clientes para lograr una mejor comunicación con su pareja.

En los tres programas el personal poseía una buena dosis de habilidades básicas. Escuchaban atentamente, tenían empatía, eran dedicados, abiertos y estaban dispuestos a aprender. Para ayudarles a que aprendieran a hablar con las/los clientes sobre sexualidad y obtuvieran un enfoque más integral respecto a la salud sexual, las/los líderes del proyecto observaron cómo las/los educadores y las/los consejeros implementaron sus nuevos conocimientos y habilidades, proporcionaron una retroalimentación inmediata e identificaron las necesidades adicionales de entrenamiento conforme el proyecto avanzaba.

Un factor clave en la preparación del personal para este proceso fue el entrenamiento sexual, el cual se centró en ayudar a las/los prestadores a que aclararan sus propios valores y prejuicios respecto a la sexualidad y las conductas sexuales. El objetivo fue permitir que el personal fuera más objetivo cuando ayudara a la clientela a entender sus propias circunstancias y a considerar sus opciones. En algunos casos, esto representó un cambio fundamental en cómo el personal se aproximó a su trabajo. Como Victoria Jennings del Proyecto de Planificación Familiar Natural de la Universidad de Georgetown observó: "Se les estaba pidiendo a las/los promotoras/es y prestadoras/es que sean facilitadoras/es y educadoras/es." Se usaron ejercicios de participación a fin de explorar varios temas: cómo sentirse cómodo con el lenguaje sexual, cómo aclarar valores, cómo explorar la propia sexualidad y el desarrollo sexual del personal de manera individual, cómo examinar los roles de género y los desequilibrios de poder, lluvia de ideas sobre otras formas de practicar el sexo seguro, cómo discutir estrategias para promover la comunicación y la negociación sexual, y cómo aclarar efecto de ciertos métodos de planificación familiar sobre las relaciones sexuales. ${ }^{1}$ Procesos como éstos también pueden alentar al personal a cambiar su propia conducta. Como una participante preguntó: “Por qué debemos esperar que nuestras/os clientes se comporten de manera más responsable que el personal, las/los directoras/ es de programas y las/los tomadoras/es de decisiones?"

No es de sorprender que una importante barrera para que las/los clientes se involucren en un diálogo más abierto acerca de sus necesidades contraceptivas es el hecho de que gran parte del personal tiene sus propias preguntas básicas en relación a la sexualidad. Cuando el personal en Honduras tuvo la oportunidad de hacer preguntas de manera anónima, preguntó: ¿Se puede practicar el sexo anal con una mujer? ¿Por qué sangré tanto durante mi primera relación sexual? ¿Es la masturbación algo malo? ¿Es el sexo oral satisfactorio? ¿Hay personas que son estimuladas sexualmente por su pareja pero que no tienen orgasmos? ¿Por qué? ¿Por qué algunas mujeres sienten miedo en el momento de la penetración? Un 
entrenamiento que permite al personal reflexionar sobre sus propios sentimientos y experiencias puede crear una autoconciencia y una empatía que influya de manera positiva en la interacción cliente-prestador/a.

Para ayudar a las/los prestadoras/es de servicios a que se sientan más cómodas/os al promover el uso del condón se requiere superar los prejuicios profesionales y personales respecto a dicho método. Varios meses después del entrenamiento en Honduras y Brasil, el personal reportó un incremento en su propio uso del condón. Una prestadora en Brasil se volvió una gran partidaria del condón y comparte con sus clientes su propia experiencia positiva. En Jamaica, personal que consideraba el condón como un método de planificación familiar menos efectivo, encontró que cuando se usan correctamente, los condones tienen un índice de eficacia potencialmente alto. El personal enseña ahora el uso adecuado de los condones. También recomienda el uso simultáneo de un método hormonal o del DIU para evitar los embarazos y el uso del condón para prevenir las ETS.

Lograr que se acepten estas ideas y enfoques nuevos ofrece una oportunidad para involucrar a un mayor número de personal-consejeras/os/educadoras/ es, enfermeras/os, médicas/os, personal administrativo, choferes y personal de limpieza-haciendo que la mayoría de la gente experimente un mayor sentido en cuanto a su misión y su importancia. En Jamaica, las recepcionistas y el chofer se enfrascan ahora en discusiones informales en la sala de espera. En Honduras, cuando no está ocupada con los Papanicolau, la citóloga inicia discusiones informales con las clientes que esperan. Como Margarita Diaz señaló, este enfoque también asegura que "los diversos mensajes dentro de una clínica lleguen adonde tienen que llegar."

Cambiar de una postura en la que simplemente se ofrece información sobre planificación familiar al hecho de involucrar a las/los clientes en una exploración de dos vías sobre su vida sexual no siempre ha resultado un proceso fácil, indicó Julie Becker. Por ejemplo, dar a la gente nuevas áreas de responsabilidad puede desafiar las estructuras tradicionales y las líneas de autoridad. La influencia de los allegados y un elemento saludable de competitividad son cosas que también han surgido. Cada centro regional trata ahora de superar las innovaciones ya incorporados por los demás. Una estrategia que resulta prometedora y que fue desarrollada en Brasil es la aplicación de intervenciones en pequeños grupos en los cuales las mujeres tienen un lugar para expresar sus preocupaciones, apoyarse unas a las otras y practicar sus capacidades de comunicación. Después de participar en varias discusiones de grupo, una mujer relató su victoria: "Después de pelearme muchas veces, logré que mi marido usara condón. Le dije que su pene era más ancho y más placentero (con el condón) y grité y gemí. Ya ha estado usando el condón durante los últimos tres meses. Ahora me siento más segura y, por supuesto, siento placer.” Becker manifestó que estos ejemplos sugieren que es posible que algunas/os clientes no estén listas para involucrar a sus propias parejas de manera directa y que se beneficiarían al hablar primero con otras/ os clientes de su mismo sexo.

Al comentar sobre el proyecto de la IPPF/RHO, Elaine Murphy de PATH señaló la necesidad de probar estas intervenciones y usar la información para establecer los beneficios para las/los clientes y el personal. Tal evidencia podría ayudar a reforzar las percepciones de las/los directores de programas en el sentido de que están teniendo un efecto positivo en lo que se refiere tanto a responder a las necesidades de las/los clientes como a la utilización de los servicios. También sería crucial procurar los fondos, el espacio y el apoyo político necesarios por parte de los donantes y las/los tomadores de decisiones de alto nivel, a fin de alentar una mayor 
experimentación. Como Murphy concluyó: “Con gran frecuencia la consigna es, 'No podemos darnos el lujo de hacer esto.' Quizás nosotras debemos demostrar que 'No podemos darnos el lujo de no hacerlo."” 

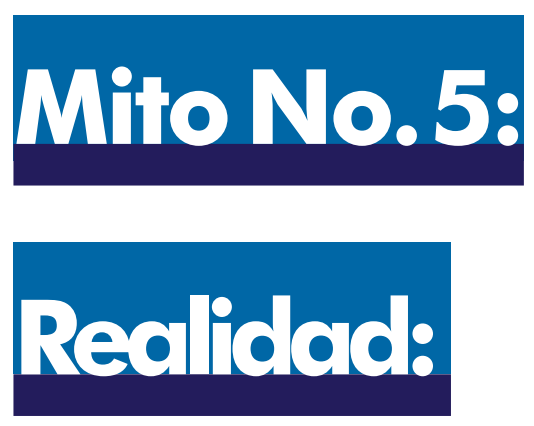

\section{Referirse a la sexualidad resultará una carga adicional para los programas de planificación familiar.}

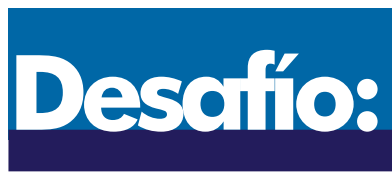

\begin{abstract}
La información disponible sobre el aumento de la satisfacción de la usuaria y sobre el uso más efectivo de anticonceptivos sugiere que el abordar el tema de la sexualidad es una inversión que vale la pena.
\end{abstract}

Ayudar a los programas de planificación familiar para que desarrollen una gama apropiada de servicios de salud sexualy reproductiva.

Las/los directoras/es de programas de planificación familiar necesitan ser guiadas/os en lo que se refiere a muchos aspectos de los servicios que podrían ser enriquecidos si se incluyen cuestiones relativas a la sexualidad. Desafortunadamente, aunque las palabras "género," "sexualidad" y "salud sexual" aparecen cada vez con mayor frecuencia en documentos políticos o de proyectos, rara vez están acompañadas por una discusión acerca de su significado o de su relación con los servicios de planificación familiar. El personal y las/los investigadoras/es que se ocupan de la planificación familiar reciben muy pocas explicaciones sobre cómo estas cuestiones pertenecen a su área de trabajo, y por consecuencia las perciben como una demanda que se añade a la prestación de servicios.

De hecho, el tiempo es algo sumamente preciado en muchas de las clínicas de planificación familiar, particularmente en América Latina, en donde mantener el financiamiento es una preocupación importante. El personal de las tres agencias afiliadas a la IPPF/RHO mencionadas en la sección anterior estaba preocupado en un principio respecto a si sus nuevas responsabilidades requerirían pasar más tiempo con cada cliente. Sin embargo, se encontraron con que, en muchos casos, si empiezan la entrevista utilizando un punto de arranque distinto-haciendo preguntas acerca de la vida sexual de la/del cliente en lugar de iniciar con una descripción de los métodos-pueden elucidar rápidamente información importante que ayuda a las/los clientes a tomar decisiones y llevarlas a la práctica en beneficio propio.

Una consejera en Honduras habló con una cliente durante varios minutos antes de descubrir que, aunque ésta había ido para solicitar un DIU, estaba preocupada de contraer una ETS de su esposo, quien viaja constantemente. La cliente no quería pedirle a su esposo que usara condones porque podría implicar una falta de confianza. Siendo madre de ocho hijos tampoco podía soportar la idea de embarazarse otra vez. Juntas, ella y su consejera decidieron que podía decirle una mentira piadosa a su marido. Ella tenía un DIU insertado como medida de apoyo, pero le dijo a su esposo que la clínica había rechazado su solicitud y que él tendría que usar condones. Aunque quizás esta estrategia no sirva para alcanzar el objetivo a largo plazo de ayudar a las/los clientes a comunicarse con sus parejas y poder tomar decisiones 
conjuntas en cuando a la reproducción, en este caso respetó la privacidad de la cliente y cubrió más de una de sus necesidades inmediatas.

En otro ejemplo, Robert Miller del Population Council presentó datos que resultaron un desafío para el supuesto tan común de que las unidades de prestación de servicios (UPS) están generalmente saturadas. Un total de catorce estudios de Análisis Situacional (valoraciones rápidas de servicios ofrecidos a y recibidos por las/los clientes) en Africa revela que el 25 por ciento de UPS sirve aproximadamente del 75 al 80 por ciento de la clientela de planificación familiar. Además, el estudio reveló cantidades importantes de capacidad que no estaba siendo usada en las tres cuartas partes de las UPS que sirven a un número relativamente bajo de clientes, dejando mucho espacio para ofrecer servicios adicionales.

De igual forma, las/los prestadoras/es de servicios también tienen oportunidades de iniciar un contacto directo con los hombres, y de hablarle a las mujeres clientes acerca de los métodos masculinos, con frecuencia rechazados. Datos de dos estudios sucesivos de Análisis Situacional efectuados en Kenya (1988 y 1995) revelan que esto puede estar ocurriendo ya. En este periodo, la proporción de clientes nuevas/os que fueron informadas/os acerca del condón aumentó de 60 a 71 por ciento; la proporción informada acerca de la vasectomía se elevó de 3 a 14 por ciento.

Jewell Quallo-Rosberg, directora ejecutiva de la Belize Family Life Association (BFLA) (Asociación de Belice para la Vida Familiar), reconoció que sí hay espacio para mejorar la forma en que los servicios de planificación familiar responden a las necesidades de salud de sus clientes. Quallo-Rosberg explicó cómo la asociación ha cambiado su foco de la planificación familiar a la salud sexual y reproductiva a nivel tanto institucional como de prestación de servicios. En la clínica, se aumentaron los servicios en un amplio rango que incluye un laboratorio de apoyo para detectar ETS y realizar pruebas de Papanicolau, dar consejería sobre prevención de SIDA, referencias para tratamientos especializados y servicios pre y posnatales para madres adolescentes en situaciones no favorables. La BFLA también está realizando un ambicioso experimento para entrenar a líderes de la comunidad como facilitadoras/es de salud reproductiva y está estableciendo un centro especial para servir a las/los adolescentes de escasos recursos.

Incorporar la educación comunitaria al trabajo de la BFLA fue un enorme reto para el personal que tuvo que cambiar de "enseñar" a los clientes a facilitar un intercambio de información. Las dos nuevas trabajadoras de campo que coordinan este componente necesitaron entrenamiento, lo mismo que las/los enfermeros en las áreas elegidas. Los talleres de entrenamiento ayudaron a las/los educadoras/es de la comunidad a darse cuenta de que el conocimiento que tenían acerca de la sexualidad era una base válida para su trabajo; pronto empezaron a confiar en su capacidad para manejar las tareas requeridas. El personal cumple ahora tres papeles simultáneos: proporciona servicios e información; crea conciencia respecto a cuáles son las causas de la mala salud y de la interacción humana pobre; y facilita y apoya los propios análisis, planificación y acción de las/los clientes. A medida que el personal de la BFLA salió de la clínica para llegar a la comunidad, ha tenido que aprender nuevas formas de maniobrar, ver y relacionar.

Las/los participantes en los talleres comunitarios incluyeron a trabajadoras/es de salud, parteras tradicionales y representantes de grupos locales dedicados a cuestiones de salud y otros de apoyo a la lactancia materna. Los objetivos de este esfuerzo de la asociación por llegar a la comunidad incluyen: (1) provisión de servicios que sean más relevantes para la vida sexual de la gente; (2) promoción de acciones comunitarias para mejorar la interacción de género, y (3) mejoramiento del uso que 
hacen las/los clientes de los servicios de referencia para otras necesidades. Las/los participantes en áreas rurales parecen ser más receptivos a estos esfuerzos que las/ los pobres urbanos, aunque ambos grupos participaron con gran entrega en los talleres iniciales. Los ejercicios sobre juego de roles generaron risa y aprendizaje, y las/los participantes aprovecharon la oportunidad para escribir poemas que reflejan sus pensamientos, sentimientos y preocupaciones respecto al sexo (ver página 28). Los hombres y las mujeres tuvieron la oportunidad de enfrascarse en una discusión abierta, de descubrir sus prejuicios y de considerar el punto de vista del otro sexo. En algunos de los talleres iniciales, varios hombres reaccionaron ante las respuestas de las mujeres saliéndose del cuarto. Esto llevó a que la BFLA entrenara a líderes en el área de discusión para que desarrollaran la capacidad de mantener abierto el flujo de la conversación.

Mientras que la BFLA cuenta con una considerable experiencia trabajando con adolescentes, en escuelas y a través de un "Club para Menores de 20," abrir un centro para jóvenes en un barrio pobre y urbano constituyó un nuevo desafío. Allí, el personal de la BFLA se encontró con un grupo de jóvenes de escasos recursos, algunos de ellos pertenecientes a pandillas, con mucha menos educación y mucha más actividad sexual que su habitual clientela adolescente. La asociación está probando nuevas estrategias para expandirse, inclusive la formación de un proyecto llamado Belizean Youth with an Aim for Prosperity (BYAP) (Juventud Beliceña con Miras a Prosperar), el cual entrena a jóvenes a través de clases de teatro como un medio para ayudarlos a comunicarse mejor con su entorno.

El nuevo programa para adolescentes ha ayudado a la BFLA a mejorar su imagen pública. Mientras que antes se consideraba que su único interés era reducir el crecimiento de la población, la asociación es vista ahora como promotora del bienestar de la juventud. Sus nuevos programas han sido cubiertos por la prensa y han generado un sentimiento de buena disposición por parte de funcionarios del gobierno, líderes religiosos y otros para colaborar en cuanto a problemas comunes.

Los cambios ocurridos a nivel clínico han permitido a la asociación responder a una gama más amplia en cuanto a las necesidad de las/los clientes. Los nuevos servicios incluyen Papanicolau y diagnóstico y tratamiento de ETS, así como referencias para tratamientos especializados. El mayor desafío en la práctica clínica fue el proceso de consejería. Como ocurrió con las tres afiliadas de IPPF cuyo trabajo es descrito anteriormente, la necesidad de aplicar un enfoque más centrado en las/ los clientes hizo que el personal se moviera más allá de la información tradicional de métodos y sus efectos colaterales a un acercamiento más interactivo y sensible a la clientela del servicio de consejería. Se desarrollaron nuevos protocolos de consejería y se re-entrenó al personal. Originalmente, el diseño del proyecto incluía un servicio prenatal a gran escala con exámenes clínicos regulares, pruebas de sangre, etc., además de servicios de información, para adolescentes. Sin embargo, a fin de mantener las cosas en un nivel manejable, la asociación se limitó a brindar el componente educativo.

En tanto más clínicas de planificación familiar comienzan a incorporar la salud sexual y reproductiva en sus programas, harían bien en prestar atención a las lecciones ya aprendidas y a los desafíos ya identificados. El éxito en el manejo de este cambio programático toma tiempo (más que una sesión de entrenamiento solamente) y flexibilidad; comunicación con las/los miembros de la comunidad; nuevas formas para reunir y evaluar información cualitativa, y la paciencia para lograr cambios de manera lenta pero segura. 


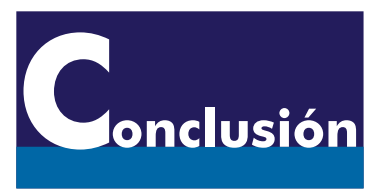

L sexualidad toca algunos de los aspectos fundamentales de la vida humana. Por lo tanto, no debería sorprender que la gente en todo el mundo valore las oportunidades que se le dan para hacer preguntas y para hablar de manera honesta y abierta acerca de su vida sexual y de sus relaciones. Sin embargo, con gran frecuencia, la sexualidad como tema de discusión es relegada a la esfera privada como algo demasiado personal como para hablar de ello inclusive con una pareja o con un miembro de la familia. La raíz de esta incapacidad para hablar francamente acerca del sexo puede no ser la vergüenza. Más bien parece ser una cierta renuencia a hablar sobre las desigualdades, y a veces abusos, de poder que existen entre compañeros íntimos. Estas desigualdades dependen de un cierto número de características-edad, raza, clase, y, muy a menudo, género-y tienen implicaciones significativas en la prestación de servicios de anticoncepción y salud reproductiva.

Con demasiada frecuencia, las mujeres-y a veces los hombres-carecen de poder para tomar decisiones y ponerlas en práctica respecto al uso de anticonceptivos y la prevención de enfermedades. Con el fin de responder de manera efectiva a esta situación, las/los investigadoras/es y directoras/es de programas deben desarrollar una mejor comprensión del contexto social en que ocurre la vida sexual y reproductiva de las/los clientes. Además de tratar de obtener más información acerca de las metas reproductivas de la clientela, las/los prestadores de servicios necesitan tener información sobre el nivel de cooperación o coerción que existe en una relación, la posibilidad de que haya otras/os compañeras/os sexuales en cualquier relación principal, y qué papel juega el sexo en la relación. ¿Están de acuerdo las/los clientes y sus parejas respecto al objetivo de limitar la fertilidad, qué método usar y quién será responsable del uso efectivo de éste? o, ¿acaso alguien en la pareja actúa de manera independiente o subrepticia para evitar un embarazo no deseado? ¿Necesitan también pensar en la prevención de enfermedades? ¿Se sienten cómodos las/los clientes con su comprensión de lo que es la fisiología reproductiva, o les gustaría tener más información? Estas preguntas pueden ayudar a las/los directoras/es de programas de planificación familiar a apreciar y responder a las necesidades de las/los clientes, así como a determinar qué resultados se tendrán.

Además, si los programas de planificación familiar expanden su objetivo de reducir el número total de nacimientos a mejorar la toma de decisiones en bien de la salud de sus clientes, deben forjar alianzas con actoras/es en sus comunidades. El poder, y las desigualdades de poder, están en la raíz de muchos resultados reproductivos no deseados y no saludables. Para alterar de manera exitosa estas relaciones, los programas de planificación familiar y de prevención del SIDA necesitarán combinar fuerzas con agencias y organizaciones que manejen las relaciones sociales de manera 
directa. Por ejemplo, necesitan capitalizar programas que estén trabajando para mejorar el acceso de las niñas y las mujeres a la educación, los créditos o la preparación para empleos, lo cual se sabe que fortalece las posiciones de las mujeres para negociar dentro de las relaciones íntimas y familiares. Necesitan trabajar con agencias de defensa e investigadoras/es que intenten definir y promover los derechos humanos de las mujeres. Necesitan salir en busca de agencias que trabajen con cuestiones relacionadas al desarrollo de la niña y del niño y para promover un mayor involucramiento paterno en la crianza de las/los hijos.

Un socio vital pero a menudo descuidado en este proceso son los medios de comunicación masiva. Herramientas como el video, la música y las historietas ilustradas pueden ser utilizadas para promover modelos alternativos de relaciones de sociedad, comportamiento sexual y negociación. Como aprendió la Belize Family Life Association, los cambios en la prestación de servicios-particularmente aquellos que respondan a los intereses de la comunidad-pueden convertirse en historias para los medios de comunicación. Además de crear una mayor visibilidad para el programa, esta clase de atención puede ayudar a sembrar la conciencia e iniciar discusiones públicas acerca de cuestiones que son difíciles de cambiar sobre bases de uno-a-uno.

Es probable que en la era post-Cairo, las/los directoras/es de programas de planificación familiar se encuentren operando en un ambiente que exige una mayor responsabilidad-tanto para las/los clientes como para los donantes-en una gama de cuestiones de salud reproductiva que incluye al VIH/SIDA y a los derechos reproductivos. Para triunfar en este ambiente, los programas de planificación familiar necesitan diseñar y evaluar servicios que estén basados en el hecho de si responden o no a las necesidades de la clientela en lo que se refiere a salud reproductiva, no en términos de cuántos anticonceptivos han distribuido o a cuántas/os clientes han servido. Estas nuevas bases requieren cambios que vayan del modelo médico que define el hecho de darle a una/un cliente la tecnología anticonceptiva más efectiva como una transacción exitosa, a un enfoque contextual a partir del cual las/los prestadoras/es de servicios y las/los directoras/es de programas consideren sus papeles como un medio para ayudar a facilitar la toma de decisiones reproductivas de manera informada por parte de sus clientes. Las dificultades para hacer esta transición no deben ser subestimadas, ni tampoco los beneficios potenciales. La sexualidad es central para los programas de planificación familiar y de salud reproductiva, particularmente aquellos que se refieren a la prevención del VIH y las enfermedades de transmisión sexual. Asimismo, como se ilustra en la presentación de este informe, la sexualidad es un tema de importancia tanto para las/los clientes como para las/los prestadores de servicios. Al tratar de manera más abierta cuestiones como el placer y el poder, los programas de planificación familiar y de salud reproductiva servirán mejor a sus clientes actuales y podrá atraer a muchas/os más clientes nuevas/os. 


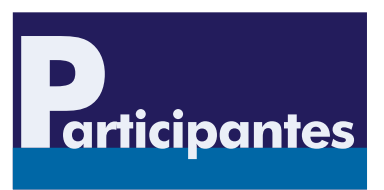

José Aguilar

Fundación Mexicana para la

Planeación Familiar (MEXFAM)

Calle Juarez 208

Tlalpan 14000 DF México

525/573-7268

Julie Becker

IPPF/WHR

120 Wall Street

New York, NY 10005

212/248-6400

Ann Blanc

DHS/Macro International Inc.

11785 Beltsville Drive, 3rd Floor

Calverton, MD 20705

301/572-0946

Debra Boyer

University of Washington

Center for Health Training

400 Tower Building

1809 7th Avenue

Seattle, WA 98101-1316

206/447-9538

Martha Brady

Population Council

One Dag Hammarskjold Plaza

New York, NY 10017

212/339-0500

George Brown

Population Council

One Dag Hammarskjold Plaza

New York, NY 10017

212/339-0500

Judith Bruce

Population Council

One Dag Hammarskjold Plaza

New York, NY 10017

212/339-0500

Stuart Burden

MacArthur Foundation

140 Dearborn Street

Suite 1100

Chicago, IL 60603

$312 / 726-8000$

Michèle Burger

Independent Consultant

11 Riverside Drive

8WE

New York, NY 10023
Lucella Campbell

IPPF/WHR

120 Wall Street

New York, NY 10005

212/248-6400

Christa Coggins

Population Council

One Dag Hammarskjold Plaza

New York, NY 10017

212/339-0500

Berengere DeNegri

Academy for Educational Development 1255 23rd Street, NW

Suite 400

Washington, DC 20037

202/884-8700

Juan Diaz

Population Council

Caixa Postal 6181

13081-970 Campinas

Sao Paulo, Brazil

55-192-392-856

Margarita Diaz

CEMICAMP

Caixa Postal 6181

CEP 13.081-970

Campinas, Sao Paulo, Brazil

55-192-392-856

Bruce Dick

UNICEF

3 UN Plaza

New York, NY 10017

212/303-7944

Diane di Mauro

Sexuality Research

Assessment Project

Social Science Research Council

810 7th Avenue

New York, NY 10019

212/377-2700

Betty Farrell

Pathfinder International

9 Galen Street

Suite 217

Watertown, MA 02172

617/924-7200 
Elizabeth Ferreras

Asociación Dominicana

Pro-Bienestar de la Familia

(PROFAMILIA)

Socorro Sanchez \# 160, Zona 1

Apartado 1053

Santo Domingo

República Dominicana

(809) 688-3566 / 689-0141

Laurie Fox

Family Health International

P.O. Box 13950

Research Triangle Park, NC 27709

919/544-7040

Judith F. Helzner

IPPF/WHR

120 Wall Street

New York, NY 10005

212/248-6400

Margaret Hempel

The Ford Foundation

320 East 43rd Street

New York, NY 10017

212/573-5000

Hilary Hughes

IPPF

Regent's College

Regent's Park

London NW14NS

United Kingdom

44-171-486-0741

Jane Hughes

The Rockefeller Foundation

420 Fifth Avenue

New York, NY 10018-2702

212/869-8500

Suzanne Hurley

Centers for Disease Control and

Prevention

Reproductive Health Unit

3005 Chamblee Tucker Road

Atlanta, GA 30341

770/488-5612

Andrea Irvin

International Women's

Health Coalition

24 East 21 st Street

New York, NY 10010

212/979-8500

Jodi Jacobson

Health and Development

Policy Project

6930 Carroll Avenue

Suite 430

Tacoma Park, MD 20912

301/270-1182
Victoria Jennings

Georgetown University

Natural Family Planning Project

School of Medicine

Dept. of OB/GYN

3800 Reservoir Road

Washington, DC 20007

202/625-3686

Ann Jimerson

Academy for Educational

Development

1255 23rd Street, NW

Suite 400

Washington DC 20037

202/884-8700

Ann Leonard

Population Council

One Dag Hammarskjold Plaza

New York, NY 10017

212/339-0500

Ronnie Lovitch

Independent Consultant

509 2nd Street

\#4R

Brooklyn, NY 11215

718/786-2655

Mia MacDonald

International Women's

Health Coalition

24 East 21 st Street

New York, NY 10010

212/979-8500

Elizabeth McGrory

Population Council

One Dag Hammarskjold Plaza

New York, NY 10017

212/339-0500

Erin McNeill

USAID

1601 North Kent Street

Roslyn, VA 22209

703/875-4793

Barbara Mensch

Population Council

One Dag Hammarskjold Plaza

New York, NY 10017

212/339-0500

Robert Miller

Population Council

One Dag Hammarskjold Plaza

New York, NY 10017

212/339-0500

Kirsten Moore

27 West Broad Street

Hopewell, NJ 08525

609/466-8788

Elaine Murphy

Program for Appropriate

Technology in Health

1990 M Street, NW

Washington, DC 20036

202/822-0033 
Sia Nowrojee

Independent Consultant

505 North Roosevelt Boulevard

B221

Falls Church, VA 22044

703/533-6978

Patricia Ospina

Asociación Pro-Bienestar de la Familia Colombiana (PROFAMILIA)

Calle 34 \# 14-52

Santa Fé de Bogota, Colombia (571) 232-9016 / 285-6967

Mary Beth Powers

Save the Children

54 Wilton Road

Wilton, CT 06881

203/221-4269

Margaret Pruitt-Clark

Advocates for Youth

1025 Vermont Avenue, NW

Suite 200

Washington, DC 20005

202/347-5700

Jewel Quallo-Rosberg

Belize Family Life Association

127 Barracks Road

P.O. Box 529

Belize City, Belize

(5012) 44-399 / 31-018

Geeta Rao Gupta

International Center for

Research on Women

1717 Massachusetts Avenue, NW

Washington, DC 20036

202/797-0007

Ann Robbins

Population Council

Center for Biomedical Research

Tower Building

1230 York Avenue

New York, NY 10021

212/327-8731

Debbie Rogow

Independent Consultant

709 West Mount Airy Avenue

Philadelphia, PA 19119

215/242-3383

Hernán Sanhueza

IPPF/WHR

120 Wall Street

New York, NY 10005

212/248-6400

Shira Saperstein

The Moriah Fund

445 North Pennsylvania Street

Suite 550

Indianapolis, IN 46204

301/951-3933
Geeta Sethi

Population Council

Zone 5A

India Habitat Centre

Lodi Road

New Delhi 110003

India

91-11-464-2901/2

James Shortridge

SIECUS

130 West 42nd Street

Room 350

New York, NY 10036

212/819-9770

Ann Starrs

Family Care International

588 Broadway

Room 510

New York, NY 10012

212/941-5300

Karen Stein

Population Council

One Dag Hammarskjold Plaza

New York, NY 10017

212/339-0500

Lindsay Stewart

305 East 24th Street

\#2G

New York, NY 10010

212/779-9259

Marcia Townley

Rockefeller Financial Services

30 Rockefeller Plaza

Suite 5600

New York, NY 10012

212/649-5600

Carlos Ugarte

Program for Appropriate

Technology in Health

1990 M Street, NW

Washington, DC 20036

202/822-0033

Mary Nell Wegner

AVSC International

79 Madison Avenue

New York, NY 10016

212/561-8000

Ann Wilson

USAID

1601 North Kent Street

Roslyn, VA 22209

703/875-4658

Beverly Winikoff

Population Council

One Dag Hammarskjold Plaza

New York, NY 10017

212/339-0500 
KIRSTEN MOORE ha compilado con Sondra Zeidenstein el libro Learning About Sexuality: A Practical Beginning y es autora con Lori Heise y Nahid Toubia de Sexual Coercion and Reproductive Health: A Focus on Research. Anteriormente, fue la gerente del Programa sobre Género, Familia y Desarrollo, del Population Council. Actualmente, está efectuando estudios para obtener una maestría en administración pública.

JUDITH F. HELZNER es la Directora de Coordinación de Programas, de la Federación Internacional de Planificación de la Familia, Región del Hemisferio Occidental. Ha trabajado en profundidad sobre temas de género, calidad de atención y salud sexual.

\section{(2) Population Council}

